\title{
What links ventilator driving pressure with survival in the acute respiratory distress syndrome? A computational study
}

\author{
Anup Das ${ }^{1} \mathbb{D}$, Luigi Camporota², Jonathan G. Hardman³ and Declan G. Bates ${ }^{1 *}$
}

\begin{abstract}
Background: Recent analyses of patient data in acute respiratory distress syndrome (ARDS) showed that a lower ventilator driving pressure was associated with reduced relative risk of mortality. These findings await full validation in prospective clinical trials.

Methods: To investigate the association between driving pressures and ventilator induced lung injury (VILI), we calibrated a high fidelity computational simulator of cardiopulmonary pathophysiology against a clinical dataset, capturing the responses to changes in mechanical ventilation of 25 adult ARDS patients. Each of these in silico patients was subjected to the same range of values of driving pressure and positive end expiratory pressure (PEEP) used in the previous analyses of clinical trial data. The resulting effects on several physiological variables and proposed indices of VILI were computed and compared with data relating ventilator settings with relative risk of death.

Results: Three VILI indices: dynamic strain, mechanical power and tidal recruitment, showed a strong correlation with the reported relative risk of death across all ranges of driving pressures and PEEP. Other variables, such as alveolar pressure, oxygen delivery and lung compliance, correlated poorly with the data on relative risk of death.

Conclusions: Our results suggest a credible mechanistic explanation for the proposed association between driving pressure and relative risk of death. While dynamic strain and tidal recruitment are difficult to measure routinely in patients, the easily computed VILI indicator known as mechanical power also showed a strong correlation with mortality risk, highlighting its potential usefulness in designing more protective ventilation strategies for this patient group.
\end{abstract}

Keywords: Mechanical ventilation, Driving pressure, Dynamic strain, Mechanical power, Tidal recruitment, Acute respiratory distress syndrome

\section{Background}

Acute Respiratory Distress Syndrome (ARDS) is characterized by acute heterogeneous inflammation of the lungs leading to deterioration in effective gas exchange [1], worsening of lung compliance [2], increasing pulmonary shunt [3], and non-cardiogenic pulmonary oedema caused by increased pulmonary vascular permeability [4]. Almost 1 in 10 intensive care admissions meet the ARDS criteria, 70\% of which are categorized as 'moderate' or 'severe' ARDS, with mortality rates exceeding 40\% [5]. The most common means of reinstating adequate oxygenation in patients with ARDS is through

\footnotetext{
* Correspondence: D.Bates@warwick.ac.uk

${ }^{1}$ School of Engineering, University of Warwick, Coventry, UK

Full list of author information is available at the end of the article
}

mechanical ventilation (MV), with the aim of meeting patients' oxygenation and $\mathrm{CO}_{2}$ removal requirements while the underlying pathology is treated. However, the lungs of patients suffering from ARDS are highly susceptible to damage introduced by mechanical ventilation, commonly known as ventilator-induced lung injury (VILI). Minimizing lung injury, while maintaining adequate gas exchange ("protective ventilation"), is thus a crucial requirement in the effective clinical management of ARDS. Currently, there is widespread confusion regarding how best to achieve protective ventilation in ARDS, with multiple debates ongoing regarding the problem. Many strategies have been proposed, and are in use; each with its own rationale, advocates and evidence of effectiveness [6-11]. Evaluating the relative

(C) The Author(s). 2019 Open Access This article is distributed under the terms of the Creative Commons Attribution 4.0 International License (http://creativecommons.org/licenses/by/4.0/), which permits unrestricted use, distribution, and 
benefits of different strategies using only traditional approaches (e.g. randomized trials) is challenging and costly, due to the number of potential strategies and disease states, and to the difficulty of recruiting critically ill patients to clinical trials.

Recently, some strong evidence associating airway driving pressure with patient mortality in ARDS was provided in two different secondary analyses of previously performed clinical trials [12, 13]. Airway-driving pressure $(\Delta \mathrm{P})$ in controlled mechanical ventilation is defined as the difference between plateau pressure and total PEEP or as the ratio of tidal volume $\left(\mathrm{V}_{\mathrm{T}}\right)$ divided by respiratorysystem compliance $\left(\mathrm{C}_{\mathrm{RS}}\right)$. Using a statistical tool known as multilevel mediation analysis, Amato and colleagues analyzed individual data from 3562 patients with ARDS enrolled in nine previously reported randomized trials, and found that a change in $\Delta \mathrm{P}$ post-randomization was the ventilator variable (mediator) that best stratified relative risk of death. A reduction in $\Delta \mathrm{P}$ owing to changes in ventilator settings was strongly associated with increased survival - independently from the randomization process [12]. Although causality could not be established, the authors speculated that $\Delta \mathrm{P}$ could be a surrogate for dynamic lung strain, and that dynamic strain might predict mortality-associated lung injury better than other physiological variables. It is also possible that - as $\Delta \mathrm{P}$ is mathematically coupled with tidal volume and elastance - the value of $\Delta \mathrm{P}$ only reflects a change in lung mechanics (i.e., elastance) which follows a change in ventilator settings, and therefore setting a specific value of $\Delta \mathrm{P}$ may not per se decrease the risk of death $[13,14]$.

Here, we investigate the physiological mechanisms underlying the above questions using a comprehensive and well-established computer simulation of integrated cardiopulmonary pathophysiology in individual ARDS patients. Twenty-five different in silico patients were simulated by independently calibrating the simulator to a clinical dataset of twenty-five adult ARDS patients, capturing the key responses to changes in mechanical ventilation. Each of these in silico patients was then subjected to the same range of values of driving pressure and positive end expiratory pressure (PEEP) suggested in [12]. The key advantage of this approach is that, in contrast to statistical analyses and clinical trials, it allows us to "look inside" the lung, and investigate the precise relationship between ventilator settings, key physiological variables, and indices of VILI. By comparing the changes in these variables over different values of $\triangle \mathrm{P}$ and PEEP with the corresponding data on patient mortality published in [12], we can investigate possible physiological mechanisms that could link driving pressure with relative risk of mortality in ARDS, and hence evaluate which VILI indicators correlate best with patient outcomes in this context.

\section{Methods}

\section{Computational model of cardio-pulmonary physiology}

The study employs a multi-compartmental computational model that simulates integrated pulmonary and cardiovascular pathophysiology [15-17]. The core models have been designed to represent a dynamic in vivo cardiovascular-pulmonary state, comprising conducting airways and a respiratory zone of 100 parallel alveolar compartments, with each compartment having a corresponding set of parameters accounting for stiffness, threshold opening pressures (TOP) and extrinsic pressures as well as airway and peri-alveolar vascular resistances. This allows for a wide spectrum of ventilation perfusion mismatch to be replicated. The model includes inherent physiological reflex mechanisms, e.g. hypoxic pulmonary vasoconstriction. The mathematical and physiological principles on which the simulator is based have been detailed in previous studies [18-21], which have also validated the simulator's capability to represent the pulmonary disease states of individual patients with chronic obstructive pulmonary disease and ARDS [15, 22]. A detailed description of the mathematical equations implementing the physiological aspects of the computational model is provided in the Supplementary Material.

\section{Patient data and simulation}

Data were extracted for adult 25 ARDS patients from Borges et al. [23]. The PF ratio (ratio of partial pressure of arterial oxygen to fraction of oxygen in inspired air) was used to assess the severity of ARDS in the patients, in accordance with the Berlin definition [24]. Of the total number of simulated patients, 13 were classified as severe (PF ratio $<100 \mathrm{mmHg}$ ), 7 were classified as moderate (PF ratio $100-200 \mathrm{mmHg}$ ) and 6 were classified as mild (PF ratio $>200 \mathrm{mmHg}$ ). An ideal body weight of 70 $\mathrm{kg}$ was assumed for all patients. All patients were assumed to be fully sedated and requiring full respiratory support through positive pressure mechanical ventilation.

The two main models of the simulator, the pulmonary model and the cardio-vascular model, were calibrated against the dataset from Borges et al. [23], using a genetic-algorithm based optimization strategy, as previously described in [17]. The key pulmonary model parameters assign airway resistances, compliances, and threshold opening pressures to each alveolar unit and also determine the characteristics of the conducting zones. These were identified at $10 \mathrm{cmH}_{2} \mathrm{O}$ of PEEP, where model outputs of PF ratio, arterial carbon dioxide tension, mixed venous oxygen saturation $\left(\mathrm{SvO}_{2}\right)$, and static compliance (Cstat) were matched to baseline data given in Borges et al. [23]. Next, the parameters of the cardiovascular (and the integrated cardio-pulmonary model), such as those governing the properties of 
cardiac chambers, major arteries and major vessels, were identified by matching the model outputs for cardiac index $(\mathrm{CI})$, arterial carbon dioxide tension $\left(\mathrm{PaCO}_{2}\right)$, mean arterial pressure (MAP) and mixed venous oxygen saturation $\left(\mathrm{SvO}_{2}\right)$ to data for varying PEEP levels, during the administration of a recruitment maneuver. All model parameters were constrained to vary between appropriate physiological ranges. Full details of the model calibration process are provided in the Supplementary Material.

\section{Measurements of key physiological variables and VILI indices}

After establishing the capability of the simulator to reproduce the responses of all 25 ARDS patients to variations in ventilator settings, measurements were made of changes in all relevant physiological variables as the in silico patients were subjected to the same levels of driving pressure and PEEP that were analyzed in the study of Amato and colleagues [12]. Driving pressure was determined as the difference between the plateau pressure and the PEEP. To observe the cardiopulmonary effects of interest, the following values were recorded: arterial oxygen tension $\left(\mathrm{PaO}_{2}\right)$, arterial carbon dioxide tension $\left(\mathrm{PaCO}_{2}\right)$, arterial $\mathrm{pH}(\mathrm{pH})$, arterial oxygen saturation $\left(\mathrm{SaO}_{2}\right)$ and $\mathrm{SvO}_{2}$, volume of individual alveolar compartments at end of inspiration and end of expiration ( $\mathrm{V}_{\text {alv_insp }}$ and $\mathrm{V}_{\mathrm{alv} \_ \text {exp }}$, respectively), and pressure of individual compartments at end of inspiration and end of expiration ( $\mathrm{P}_{\mathrm{alv} \_ \text {insp }}$ and $\mathrm{P}_{\mathrm{alv} \_ \text {exp }}$, respectively), cardiac output ( $\mathrm{CO}$; cardiac index was calculated from $\mathrm{CO}$ indexed to body surface area), the mean arterial pressure (MAP), the mean pulmonary artery pressure (MPAP) and oxygen delivery $\left(\mathrm{DO}_{2}\right.$; using the values of $\mathrm{CO}, \mathrm{SaO}_{2}$ and $\mathrm{PaO}_{2}$ and given hemoglobin level $(\mathrm{Hb})$ ). Recruitment was calculated as the fraction of alveoli receiving zero ventilation subsequently achieving ventilation. Several proposed indices of VILI were calculated, e.g. respiratory system compliance $\left(C_{R S}\right)$ [25], intra-tidal recruitment [26, 27], mechanical power [28], mean alveolar pressure $\left(P_{a l v}\right)$ [29], and the strain on the lung (both dynamic and static [30]). $C_{R S}$ is calculated as $\Delta \mathrm{V} /$ ( $\mathrm{P}_{\text {plat }}$ - PEEP), where $\mathrm{P}_{\text {plat }}$ is the plateau pressure. The dynamic strain is calculated as $\Delta \mathrm{V} / \mathrm{V}_{\text {frc }}$, where $\mathrm{V}_{\text {frc }}$ is $\mathrm{V}_{\text {alv_exp }}$ at PEEP $=0 \quad \mathrm{cmH}_{2} \mathrm{O}$ and $\Delta \mathrm{V}=\mathrm{V}_{\text {alv_insp }}-\mathrm{V}_{\text {alv_exp. }}$. Static strain was calculated as $\mathrm{V}_{\text {alv_exp }} / \mathrm{V}_{\text {frc }}$. Intra-tidal recruitment was calculated as the difference between the fraction of total ventilated lung at the end of inhaling and end of exhaling, expressed as a percentage. The mean alveolar pressure, $P_{a l v}$ is calculated as the average end-inspiratory pressure (of the highest 20\% values) distributed across the lung, which is a better indicator for end-inspiratory lung pressure than the often used surrogate, plateau pressure. Gattinoni and colleagues [28, 31,
32] have suggested that instead of separately considering the mechanical factors (pressure, volume, rate and flow) associated with VILI, it may be better to combine these factors as the 'mechanical power' imparted to the lung by the ventilator, which we calculated using the following equation (Eq. 6 from [28]):

$$
\underset{J m_{i n}^{-1}}{\operatorname{Power}}=0.098 \cdot V R \cdot\left\{V_{T}^{2} \cdot\left[\frac{1}{2} \cdot E+V R \cdot \frac{(1+I E)}{60 \cdot I E} \cdot R_{a w}\right]+V_{T} \cdot P E E P\right\}
$$

Here, $V R$ is the respiratory rate set by the ventilator, $V_{T}$ is the ventilator delivered tidal volume, $E$ is the elastance of the respiratory system (calculated as $1 / C_{R S}$ ), $I E$ is calculated as the inhalation time/ exhalation time in a single breath, $R_{a w}$ is the airway resistance calculated using the difference in peak pressure and plateau pressure at the ventilator and resultant flow $\left(V_{T} /\right.$ inspiratory time) during a breath, and PEEP is the total positive end-expiratory pressure. During simulations, all parameters were recorded every 10 milliseconds. All simulations, model calibration and data analysis were performed within the Matlab $^{\odot}$ 2015a programming environment.

\section{Results}

\section{Computational model calibration results}

The results of calibrating the model against data on 25 ARDS patients reported in Borges et al. [23] are given in Fig. 1. All model outputs of interest were consistently very close to the values reported in the clinical data (overall $r^{2}>0.94, p<0.00001$ ), thus supporting the ability of the simulator to reproduce the physiological responses of each individual patient. Figure 1 reports the mean and standard deviation for the data and model outputs across the patient cohort. A comparison of model outputs versus individual patient data for all 25 patients is provided in the Supplementary Material. Baseline characteristics of the simulated patients are listed in Table 1.

\section{Comparing VILI indices with mortality risk for different $\Delta \mathrm{P}$ and PEEP settings}

Figures 2 and 3 show the responses of key physiological variables (in blue) for the same variations in $\Delta \mathrm{P}$ and PEEP levels used in [12], across the patient cohort. Figures 2 and 3 also show the relative risk of mortality (in red) as reported in [12], for the corresponding $\Delta \mathrm{P}$ /PEEP levels, with values higher than 1 indicating increased mortality rate after multivariate adjustment (for details see supplementary material of [12]). Of all indices of VILI investigated, only dynamic lung strain, mechanical power, and tidal recruitment were strongly positively correlated $(\mathrm{r}>0.85, p<0.05)$ with the mortality risk to changes in $\Delta \mathrm{P}$ reported in [12] (Table 2). Larger $\Delta \mathrm{P}$ values, while keeping PEEP constant, led to significant 


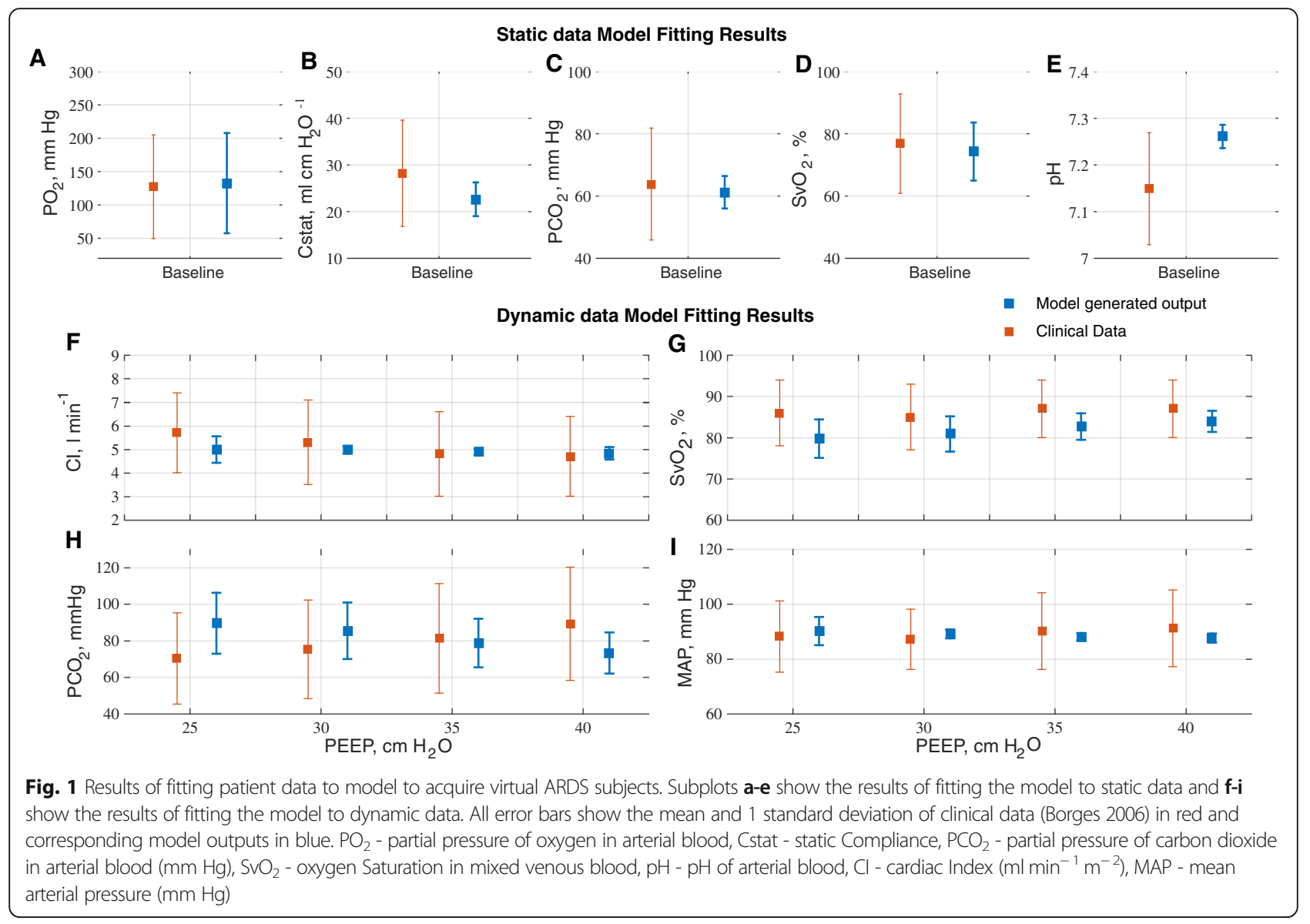

increases in dynamic strain (Fig. 2d), mechanical power (Fig. 2j) and tidal recruitment (Fig. 2g) that were strongly and significantly correlated with increases in relative risk of mortality, $(r=0.99,0.99$ and 0.96 respectively, with $\mathrm{p}<0.05$ ). On the other hand, higher plateau pressures caused by using higher PEEP values while keeping $\Delta \mathrm{P}$ constant, resulted in very small increases in dynamic strain and tidal recruitment, consistent with the lack of effect on mortality risk reported in [12] (Fig. 2e, $h, k)$. Finally, higher PEEP values combined with lower $\Delta \mathrm{P}$ led to significant decreases in dynamic strain (Fig. 2f), mechanical power (Fig. 2l) and tidal recruitment (Fig. 2i), which were strongly correlated with the decreased relative risk of mortality reported in [12] $(r>$ $0.95, p<0.01$ for all cases).

Other potential VILI indices, including dynamic compliance, alveolar pressure and static strain, were also calculated, but showed significant deviations from the data on patient mortality as driving pressure and/or PEEP were varied. They are illustrated in Fig. 3 along with peripheral oxygen delivery, cardiac output and $\mathrm{PaO}_{2} / \mathrm{FiO}_{2}$ (PF) ratio, with corresponding correlation coefficients reported in Table 2. Increases in lung compliance,
Table 1 Characteristics of in silico patients at baseline

\begin{tabular}{|c|c|}
\hline & Baseline \\
\hline & Mean (SD) \\
\hline $\mathrm{PaCO}_{2}, \mathrm{mmHg}$ & $61(5.2)$ \\
\hline $\mathrm{pH}$ & $7.24(0.03)$ \\
\hline $\mathrm{SvO}_{2}, \%$ & $74(9.3)$ \\
\hline Shunt Fraction, \% & $34(11.3)$ \\
\hline $\mathrm{Cl}, \mathrm{L} \min ^{-1} \mathrm{~m}^{-2}$ & $5(0.3)$ \\
\hline MAP, $\mathrm{mm} \mathrm{Hg}$ & $90(2.6)$ \\
\hline PF ratio, $\mathrm{mmHg}$ & $133(75)$ \\
\hline - Mild & $244(37)$ \\
\hline - Moderate & $152(37)$ \\
\hline - Severe & $72(9.6)$ \\
\hline Cstat, $\mathrm{ml} \mathrm{cmH}_{2} \mathrm{O}^{-1}$ & $22(3.6)$ \\
\hline$V R$, breaths $\min ^{-1}$ & $12.5(0.8)$ \\
\hline$V_{T}, \mathrm{ml}$ PBW & $5.9(0.08)$ \\
\hline
\end{tabular}

$\mathrm{Cl}$ - Cardiac Index (indexed to body surface area), $\mathrm{FiO}_{2}$ - Fraction of $\mathrm{O}_{2}$ in inspired gas, PEEP - Positive End Expiratory Pressure, PF ratio - Ratio of Arterial oxygen tension to $\mathrm{FiO}_{2}, \mathrm{PaCO}_{2}$ - Arterial carbon dioxide tension, $\mathrm{SvO}_{2}$ - Mixed Venous Oxygen Saturation, Cstat - Static Compliance, MAP - Mean Arterial pressure, $V R$ - Respiratory Rate, $\Delta V$ - Tidal Volume

Baseline in silico patients at PEEP $5 \mathrm{~cm} \mathrm{H}_{2} \mathrm{O}, \mathrm{FiO}_{2} 1.0$, plateau pressure 30 $\mathrm{cmH}_{2} \mathrm{O}$. PF ratio and Cstat recorded at PEEP $10 \mathrm{cmH}_{2} \mathrm{O}$ (as given in (15)) 


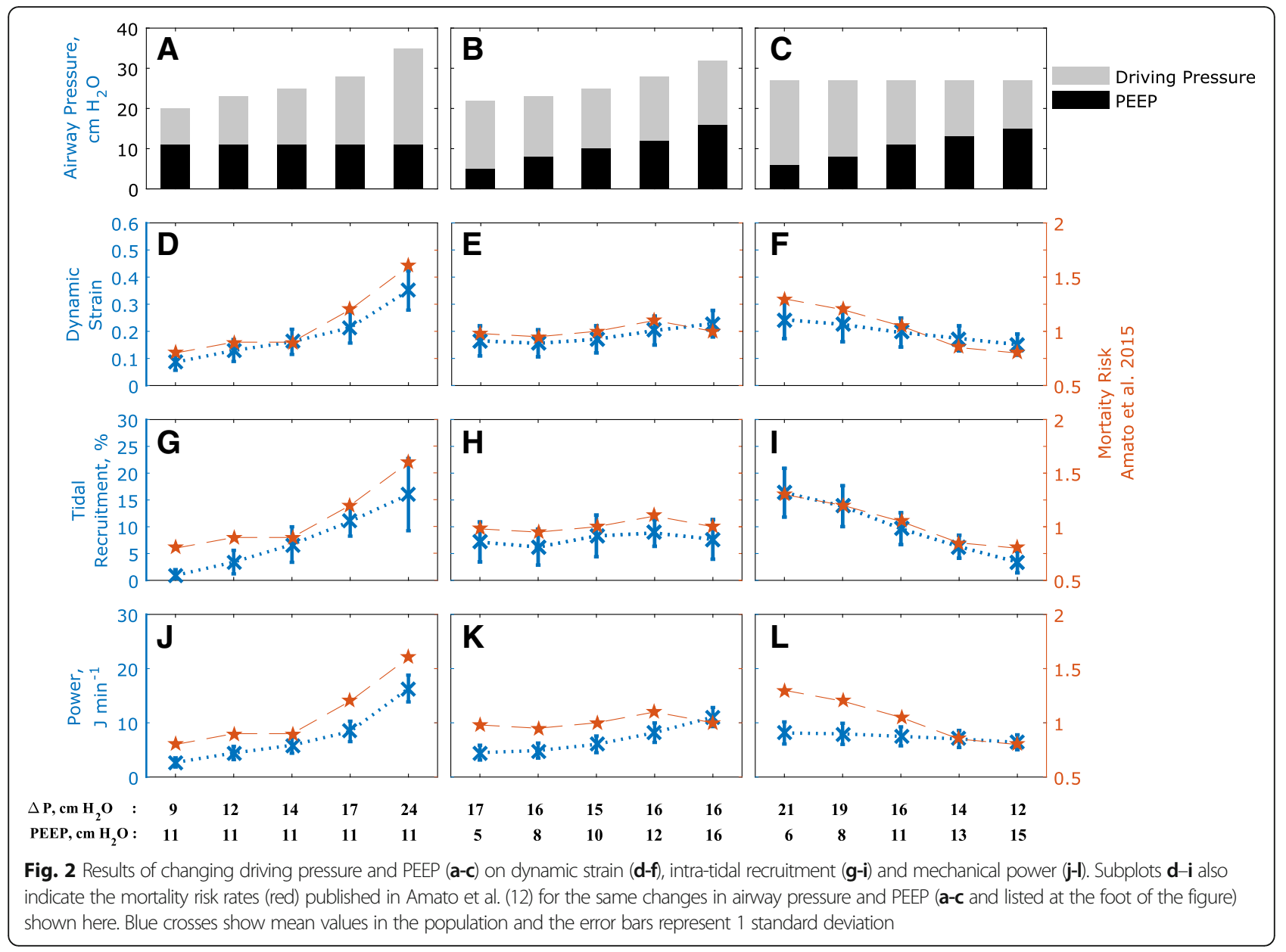

average pressure across the lung, static strain and PF ratio were observed with increasing PEEP or driving pressure. Lowering driving pressures by increasing PEEP did not result in any adverse outcomes with respect to oxygenation (Fig. 3l, r). There were no significant effects on cardiac output in all three interventions (Fig. 3m-o). Static strain rose considerably across the three interventions (Fig. 3s-u), but the biggest rise was observed in the constant $\triangle \mathrm{P}$ with higher PEEP group (Fig. 3t). Individual results for all 25 patients are reported in the supplementary material.

\section{Discussion}

The current standard recommendation for providing lung protective ventilation in patients with ARDS supports the use of low tidal volumes (LTV) while integrating higher levels of PEEP. In the seminal ARDS Network (ARDSnet) study [33], this LTV protective strategy resulted in significantly improved survival rates when compared to the then 'traditionally-used' higher tidal volumes. Since then, however, various studies have failed to show further uniform benefits of LTV in ARDS patients $[10,11,34]$. These studies found that even with the use of the proposed ARDSnet protocol, the mortality rate in ARDS patients remained relatively high ( $>40 \%$ [34]), which was attributed to the probable tidal hyperinflation of the normally aerated part of the lungs. By itself, therefore, it seems clear that LTV is not sufficient to achieve a lung protective ventilation. In 2015, Amato and colleagues [12] presented the results of a retrospective analysis of individual patient data, with the conclusion that the driving pressure (tidal volume normalized to lung compliance) was better associated to survival in ARDS patients than either tidal volume or plateau pressure separately. Following this, various studies have corroborated those results [13,35], and shown that driving pressure was a good indicator of lung stress [36], higher driving pressures were associated with more postoperative pulmonary complications [35], and higher driving pressures may induce lung injury more easily in patients with low respiratory system compliance [37]. The results in this paper support the hypothesis that higher driving pressure results in increases in several important indices of VILI.

More recently, a trial involving a patient cohort of 1010 patients with moderate to severe ARDS found that 


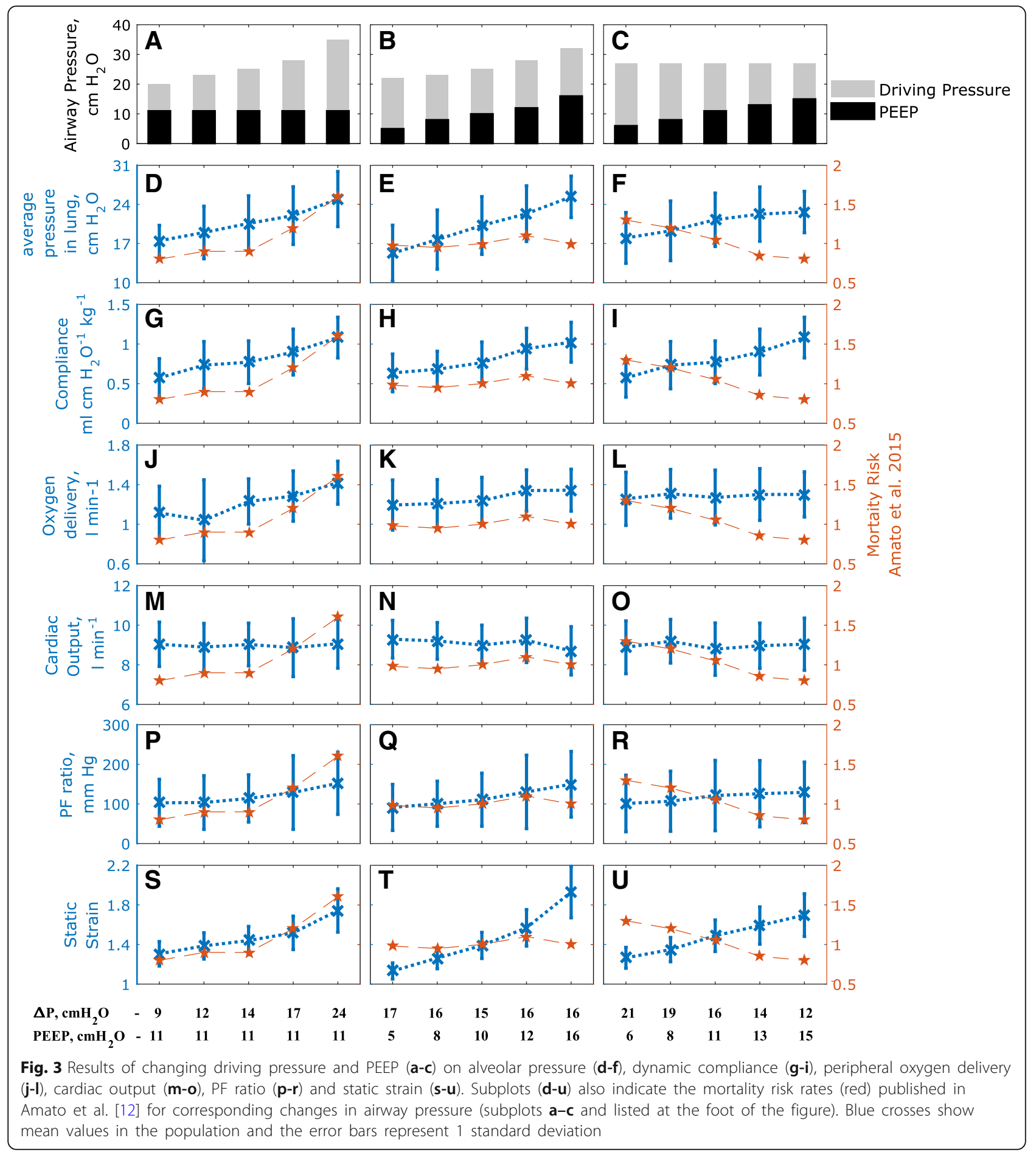

the use of higher PEEP values (titrated to optimal respiratory system compliance) without significant deviations in driving pressure, were associated with higher risk of mortality [38]. In our virtual patient cohort, this ventilation strategy was associated with significant increases in mechanical power (Fig. 2k), alveolar pressure (Fig. 3e) and static strain (Fig. 3t). The lack of significant change in overall mortality in the Amato study [12] in this case may be due to the significant number of mild ARDS patients in that cohort, who would have tolerated the higher plateau pressures better. At the same time, our results indicate that increases in PEEP that were accompanied by significant decreases in $\Delta \mathrm{P}$ result in reductions in the intra-tidal opening and closing of lung 
Table 2 Correlation coefficients of outputs with respect to mortality data

\begin{tabular}{|c|c|c|c|c|c|c|c|}
\hline \multirow[t]{2}{*}{ Model Parameter } & \multicolumn{2}{|c|}{$\begin{array}{c}\text { Increasing DP constant } \\
\text { PEEP }\end{array}$} & \multicolumn{2}{|c|}{$\begin{array}{c}\text { Constant DP Increasing } \\
\text { PEEP }\end{array}$} & \multicolumn{2}{|c|}{ Reducing DP Increasing PEEP } & \multirow{2}{*}{$\begin{array}{c}\text { Average } \\
r\end{array}$} \\
\hline & r & $\mathrm{p}$ & $r$ & $\mathrm{p}$ & $r$ & $\mathrm{p}$ & \\
\hline Dynamic Strain & 0.985 & 0.002 & 0.534 & 0.353 & 0.989 & 0.001 & 0.836 \\
\hline Tidal Recruitment & 0.960 & 0.010 & 0.879 & 0.049 & 0.992 & 0.001 & 0.944 \\
\hline Mechanical Power & 0.987 & 0.002 & 0.451 & 0.446 & 0.969 & 0.007 & 0.802 \\
\hline $\begin{array}{l}\text { Mean Alveolar } \\
\text { Pressure }\end{array}$ & 0.956 & 0.011 & 0.495 & 0.397 & -0.981 & 0.003 & 0.157 \\
\hline Dynamic Compliance & 0.959 & 0.010 & 0.612 & 0.273 & -0.948 & 0.014 & 0.208 \\
\hline Oxygen Delivery & 0.886 & 0.045 & 0.721 & 0.170 & -0.556 & 0.331 & 0.350 \\
\hline Cardiac Output & 0.178 & 0.775 & 0.087 & 0.890 & -0.036 & 0.954 & 0.076 \\
\hline PF ratio & 0.984 & 0.002 & 0.507 & 0.383 & -0.974 & 0.005 & 0.172 \\
\hline Static Strain & 0.981 & 0.003 & 0.392 & 0.514 & -0.989 & 0.001 & 0.128 \\
\hline VD/VT & -0.935 & 0.020 & -0.705 & 0.184 & -0.880 & 0.049 & -0.840 \\
\hline
\end{tabular}

The table reports the Pearson linear correlation coefficient ( $r$ ) between the simulated outputs and mortality data reported in 12, with corresponding $p$ value using the students $t$ distribution. Shaded areas highlight parameters with strong positive and significant correlations with mortality data $(r>0.85, p<0.05)$. Table ordered in descending order for average r. PF ratio is the ratio of arterial oxygen tension to fraction of $\mathrm{O}_{2}$ in inspired air. VD/VT is the physiological deadspace fraction

units (Fig. 2l), together with increased lung compliance (Fig. 3i). These results lend further weight to the argument that the key goal in attempting to provide more protective ventilation should be to achieve significant reductions in driving pressure.

Many different potential physiological indicators of VILI have been proposed in the literature, but in almost all cases, their direct effect on patient mortality has not been conclusively established. Furthermore, ventilator effects leading to hemodynamic impairment are rarely considered in the context of VILI, even though pulmonary vascular dysfunction and acute cor pulmonale are well recognized outcomes in ARDS $[39,40]$, even during protective ventilation $[41,42]$. By inserting a detailed model of cardiopulmonary physiology between the data linking ventilator settings and relative risk of mortality published in [12], we can investigate which physiological mechanisms correlate best with patient mortality. With respect to VILI, markers of lung injury attempt to quantify the potentially destructive contribution of mechanical forces to exacerbating pre-existing lung pathology. One such marker is the dynamic lung strain [43], which accounts for the increase in tissue tensions and detrimental effects of dynamic tidal excursions. The results of this paper suggest that dynamic strain correlates well with the changes in mortality rates observed for varying values of driving pressure. The authors of [12] recognize this as a possible explanation for their findings, and the results provided here provide further support for this hypothesis.
Although our results indicate that dynamic strain provides a plausible physiological mechanism to explain the effect of driving pressure on patient mortality, this is not a quantity that can be readily and accurately calculated by clinicians at the bedside. There is also a reasonable argument that it is the combination of multiple dynamic components of ventilation, e.g. frequency, strain rate, etc. alongside variables such as stress and strain that may accentuate the risk of lung injury in ARDS patients [44]. Gattinoni and colleagues [14, 31] have proposed the concept of 'mechanical power' as a determinant of VILI, combining key ventilator settings and lung mechanics into a single mathematical equation which can be readily computed. The results presented in Fig. 2 and Table 2 show mechanical power to be strongly correlated with mortality rates published in [12] for the given changes in driving pressures and PEEP.

It should be noted from Fig. 2 that the only $\triangle \mathrm{P} / \mathrm{PEEP}$ values for which the mechanical power was significantly higher than $12 \mathrm{~J} / \mathrm{min}$ (Fig. 2i) (the maximum value recommended by Guerin et al. [13], who associated staying below this threshold with higher survival rates) was at a driving pressure of $24 \mathrm{cmH}_{2} \mathrm{O}$ and PEEP of $11 \mathrm{~cm} \mathrm{H}_{2} \mathrm{O}$. It can be clearly seen across the cohort that despite the overall increase in PEEP and plateau pressures, the improvement in lung compliance (Fig. 3i) and lower driving pressures do not result in a significant rise in delivered mechanical power. It should be noted that the investigation in this paper was limited to comparing the 
effects of the driving pressure values given in [12], which did not account for mechanical power or explicitly report key components for calculating power, i.e. respiratory rate, duty cycle, airway resistances etc. The overall positive correlation to mortality rates (Table 2), however, supports mechanical power as a potentially important indicator of lung injury in ARDS patients.

Dynamic strain accounts for normally-aerated lung regions in ARDS [45] as well as the intra-tidal recruitment of alveolar units. However, studies [46] have suggested that strain and intra-tidal opening and closing of alveolar units should be considered independently. In clinical investigations, the amount of recruited lung is often determined using whole lung CT scans and chest $\mathrm{x}$-ray, or estimated using pressure volume curves. The computational model used in our study allows for the direct and continual assessment of the total recruited lung region the resulting measure of 'tidal recruitment' (the amount of newly recruited lung during tidal ventilation) is a distinctive indicator for VILI. The results of this study show a strong correlation between the reported mortality data and tidal recruitment for the investigated variations in driving pressure $(\mathrm{r}>0.85, p<0.05$ in all strategies). The results indicate that reducing $\Delta \mathrm{P}$ from $21 \mathrm{~cm} \mathrm{H}_{2} \mathrm{O}$ to 12 $\mathrm{cm} \mathrm{H}_{2} \mathrm{O}$ reduced intra-tidal opening and closing of alveolar units from an average of $16 \%$ to below $4 \%$ of the total lung. Tidal recruitment thus offers another potentially valuable marker for lung injury in ARDS for investigation in future prospective studies.

Several other important physiological variables were also evaluated in this study; including lung compliance, end inspiratory lung pressures, PF ratio, static strain, cardiac output and oxygen delivery to peripheral tissue. Generally, the correlation between these indicators and reported mortality rates observed with respect to changes in $\Delta \mathrm{P}$ was weak. As expected, the average lung pressures increased uniformly across the three interventions accompanying increases in ventilator pressures. Lung compliance, PF ratio, and static strain also increased with ventilator pressures, indicating betteraerated regions, improved ventilation/perfusion mismatch and increased end-expiratory lung volumes, respectively.

The study described in this manuscript has some limitations. The patient data used was collected from patients with high baseline values of cardiac output (CO). These values are consistent with the data in [23], which reported a mean cardiac index of $5.81 \mathrm{~min}^{-1} \mathrm{~m}^{-2}$ at plateau pressure of $30 \mathrm{cmH}_{2} \mathrm{O}$ in their patient cohort. The ability to draw conclusions about the precise presence or absence of cardiopulmonary dysfunction is limited from the information available in the published data sets. However our simulations do exhibit the cyclical changes in venous, ventricular and arterial systems observed in response to positive pressure ventilation $[16,17,47]$.
Parameters such as ventilation rate (VR) and duty cycle (DC) were left at baseline settings (determined at model calibration stage) throughout the simulations, due to limited availability data and no systematized guidelines available for prospective $\Delta \mathrm{P}$ adjustment. It should also be noted that the studies that provided the data used for model calibration reported no significant changes in heart rate throughout their interventions, making it likely that the drugs and dosages used for sedation suppressed normal cardiovascular system baroreceptor reflexes. As such, autonomic reflex modules of the model could not be calibrated, and hence were not utilized. The measured alveolar strain was used as a surrogate for the effects of increased inflammatory mediators found in ARDS, whose effects are otherwise difficult to isolate and quantify in clinical settings [48]. Finally, any computational model will be an approximation of the relevant physiological processes and cannot reflect all the inherent complexity of the underling pathophysiology.

\section{Conclusions}

It is clear that ARDS encompasses multiple different aetiologies, with different outcomes, and thus mortality rates can never be determined solely by any single factor, including VILI. Nevertheless, the results in this paper suggest a plausible physiological basis for the recently proposed link between driving pressure and mortality in ARDS, that could be tested in future clinical studies. Using a high-fidelity computational simulator of cardiopulmonary pathophysiology, we observe that cyclic alveolar strain combined with tidal recruitment may provide a credible mechanistic explanation for the proposed association between higher driving pressures and greater relative risk of death in ARDS. While these indices are difficult to measure directly in patients, the easily-computed VILI indicator known as mechanical power also showed a strong correlation with mortality risk, highlighting its potential usefulness in testing these hypotheses, and in designing more protective ventilation strategies for this patient group.

\section{Additional file}

Additional file 1: Computational model, calibration and additional results. Description of entire computational model, calibration process to fit model to data, fitting results to individual data and dataset from simulation results for. (PDF 2027 kb)

\section{Abbreviations}

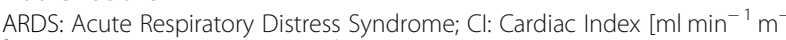
2]; CO: Cardiac output [ml $\mathrm{min}^{-1}$ ]; $\mathrm{C}_{\mathrm{RS}}$ : Respiratory System Compliance [ml $\mathrm{CmH}_{2} \mathrm{O}^{-1}$ ]; DC: Duty Cycle, inspiration time/ total time for 1 breath; $\mathrm{DO}_{2}$ : Oxygen delivery $\left[\mathrm{ml} \mathrm{min}{ }^{-1}\right] ; \mathrm{FlO}_{2}$ : Fraction of inspired air constituting of oxygen; Hb: Haemoglobin content in blood [gm $\mathrm{I}^{-1}$ ]; IE: Inspiration time/ expiration time; LTV: Low Tidal Volume; a lung protective mechanical ventilation strategy; MAP: Mean Arterial Pressure [mm Hg]; MPAP: Mean 
Pulmonary Arterial pressure $[\mathrm{mm} \mathrm{Hg}] ; \mathrm{PaCO}_{2}$ : Partial pressure of carbon dioxide in arterial compartment [kpa]; $\mathrm{P}_{\mathrm{alv}}$ : Mean alveolar pressure; $\mathrm{PaO}_{2}$ : Partial pressure of oxygen in arterial compartment [kpa]; PEEP: Positive End Expiratory Pressure [ $\left.\mathrm{cm} \mathrm{H}_{2} \mathrm{O}\right]$; PF ratio: Ratio of arterial pressure of oxygen to fraction of oxygen in inspired air; $\mathrm{pH}$ : Arterial $\mathrm{pH}$ value; $P_{\text {IT: }}$ Intrathoracic pressures; Pplat: Plateau pressure $\left[\mathrm{cm} \mathrm{H}_{2} \mathrm{O}\right] ; \mathrm{PvO}_{2}$ : Partial pressure of mixed venous oxygen [kpa]; Raw: Airway resistance; RQ: Respiratory Quotient; $\mathrm{SaO}_{2}$ : Arterial oxygen saturation; $\mathrm{SvO}_{2}$ : Venous oxygen saturation; $V_{\text {frc: }}$ End Expiratory lung volume at $P E E P=0 \mathrm{cmH}_{2} \mathrm{O}$; VILI: Ventilator Induced Lung Injury; VO2: Oxygen consumption [ml $\mathrm{min}^{-1}$ ]; VQ: Ventilation Perfusion; VR: Respiration rate set by the ventilator [breaths per minute, bpm]; $\mathrm{V}_{\mathrm{T}}$ : Ventilator delivered tidal volume $[\mathrm{ml}] ; \Delta \mathrm{P}$ : Airway driving pressure, difference between plateau pressure and total PEEP [ $\left.\mathrm{cm} \mathrm{H}_{2} \mathrm{O}\right]$

\section{Acknowledgements}

Not Applicable.

\section{Funding}

UK Engineering and Physical Sciences Research Council (grant number EP/ P023444/1).

\section{Availability of data and materials}

Any dataset or resources used in the current study may be available from the corresponding author on reasonable request. Patient data obtained from Borges JB, Okamoto VN, Matos GF, Caramez MP, Arantes PR, Barros F, et al. Reversibility of lung collapse and hypoxemia in early acute respiratory distress syndrome. Am J Respir Crit Care Med. 2006;174(3):268-78. See Additional file 1 for description of entire computational model, calibration process to fit model to data, fitting results to individual data and dataset from simulation results for individual patients.

\section{Authors' contributions}

$J G H, A D$, and $D G B$ designed and implemented the computational model and disease simulation. $A D$, and DGB developed algorithms for automated matching of the simulator to individual patient data. $\mathrm{LC}$ and $\mathrm{JH}$ analyzed the results, and provided clinical interpretations of simulator outputs. All authors contributed to successive drafts of the manuscript, and read and approved the final manuscript.

\section{Ethics approval and consent to participate}

Not Applicable.

\section{Consent for publication}

Not Applicable.

\section{Competing interests}

The authors declare that they have no competing interests.

\section{Publisher's Note}

Springer Nature remains neutral with regard to jurisdictional claims in published maps and institutional affiliations.

\section{Author details \\ ${ }^{1}$ School of Engineering, University of Warwick, Coventry, UK. ${ }^{2}$ Intensive Care Medicine, Guy's and St Thomas' NHS Foundation Trust and Division of Asthma Allergy and Lung Biology, King's College London, London, UK. ${ }^{3}$ Queen's Medical Centre, Nottingham University Hospitals NHS Trust and School of Medicine, University of Nottingham, Nottingham, UK}

Received: 21 November 2018 Accepted: 23 January 2019 Published online: 11 February 2019

\section{References}

1. Dantzker DR, Brook CJ, Dehart P, Lynch JP, Weg JG. Ventilation-perfusion distributions in the adult respiratory distress syndrome. Am Rev Respir Dis. 1979:120:1039-52.

2. Murray JF, Matthay MA, Luce JM, Flick MR. An expanded definition of the adult respiratory distress syndrome. Am Rev Respir Dis. 1988;138:720-3.

3. Dantzker D, Lynch J, Weg J. Depression of cardiac output is a mechanism of shunt reduction in the therapy of acute respiratory failure. Chest. 1980;77: 636-42.
4. Ranieri VM, Rubenfeld GD, Thompson BT, Ferguson ND, Caldwell E, Fan E, Camporota L, Slutsky AS. Acute respiratory distress syndrome: the Berlin definition. JAMA. 2012;307:2526-33.

5. Bellani G, Laffey JG, Pham T, Fan E, Brochard L, Esteban A, Gattinoni L, van Haren F, Larsson A, McAuley DF, et al. Epidemiology, patterns of care, and mortality for patients with acute respiratory distress syndrome in intensive care units in 50 countries. JAMA. 2016;315:788-800.

6. Brower RG, Lanken PN, Maclntyre N, Matthay MA, Morris A, Ancukiewicz M, Schoenfeld D, Thompson BT, National Heart L, Blood Institute ACTN. Higher versus lower positive end-expiratory pressures in patients with the acute respiratory distress syndrome. N Engl J Med. 2004;351:327-36.

7. Mercat A, Richard JC, Vielle B, Jaber S, Osman D, Diehl JL, Lefrant JY, Prat G, Richecoeur J, Nieszkowska A, et al. Positive end-expiratory pressure setting in adults with acute lung injury and acute respiratory distress syndrome: a randomized controlled trial. JAMA. 2008;299:646-55.

8. Spieth PM, Gama de Abreu M. Lung recruitment in ARDS: we are still confused, but on a higher PEEP level. Crit Care. 2012;16:108.

9. Meade MO, Cook DJ, Guyatt GH, Slutsky AS, Arabi YM, Cooper DJ, Davies AR, Hand LE, Zhou Q, Thabane L, et al. Ventilation strategy using low tidal volumes, recruitment maneuvers, and high positive end-expiratory pressure for acute lung injury and acute respiratory distress syndrome: a randomized controlled trial. JAMA. 2008;299:637-45.

10. Terragni PP, Rosboch G, Tealdi A, Corno E, Menaldo E, Davini O, Gandini G, Herrmann P, Mascia L, Quintel M, et al. Tidal hyperinflation during low tidal volume ventilation in acute respiratory distress syndrome. Am J Respir Crit Care Med. 2007:175:160-6.

11. Grasso S, Stripoli T, De Michele M, Bruno F, Moschetta M, Angelelli G, Munno I, Ruggiero V, Anaclerio R, Cafarelli A, et al. ARDSnet ventilatory protocol and alveolar hyperinflation: role of positive end-expiratory pressure. Am J Respir Crit Care Med. 2007;176:761-7.

12. Amato MB, Meade MO, Slutsky AS, Brochard L, Costa EL, Schoenfeld DA, Stewart TE, Briel M, Talmor D, Mercat A, et al. Driving pressure and survival in the acute respiratory distress syndrome. N Engl J Med. 2015;372:747-55.

13. Guerin C, Papazian L, Reignier J, Ayzac L, Loundou A, Forel JM. Investigators of the a, Proseva t. Effect of driving pressure on mortality in ARDS patients during lung protective mechanical ventilation in two randomized controlled trials. Crit Care. 2016;20:384.

14. Tonetti T, Vasques F, Rapetti F, Maiolo G, Collino F, Romitti F, Camporota L, Cressoni M, Cadringher P, Quintel M, Gattinoni L. Driving pressure and mechanical power: new targets for VILI prevention. Ann Transl Med. 2017:5:286.

15. Das A, Cole O, Chikhani M, Wang W, Ali T, Haque M, Bates DG, Hardman JG. Evaluation of lung recruitment maneuvers in acute respiratory distress syndrome using computer simulation. Crit Care. 2015;19:8.

16. Chikhani M, Das A, Haque M, Wang W, Bates DG, Hardman JG. High PEEP in acute respiratory distress syndrome: quantitative evaluation between improved arterial oxygenation and decreased oxygen delivery. Br J Anaesth. 2016;117:650-8.

17. Das A, Haque M, Chikhani M, Cole O, Wang W, Hardman JG, Bates DG. Hemodynamic effects of lung recruitment maneuvers in acute respiratory distress syndrome. BMC Pulm Med. 2017;17:34.

18. Hardman J, Bedforth N, Ahmed A, Mahajan R, Aitkenhead A. A physiology simulator: validation of its respiratory components and its ability to predict the patient's response to changes in mechanical ventilation. Br J Anaesth. 1998;81:327-32.

19. McNamara MJ, Hardman JG. Hypoxaemia during open-airway apnoea: a computational modelling analysis. Anaesthesia. 2005;60:741-6.

20. McCahon R, Columb M, Mahajan R, Hardman J. Validation and application of a high-fidelity, computational model of acute respiratory distress syndrome to the examination of the indices of oxygenation at constant lung-state. Br J Anaesth. 2008;101:358-65.

21. Das A, Haque M, Cole O, Chikhani M, Wang W, Ali T, Bates DG, Hardman JG. Development of an Integrated Model of Cardiovascular and Pulmonary Physiology for the Evaluation of Mechanical Ventilation Strategy. In 37th IEEE Engineering in Medicine and Biology Conference, Milano, Italy; Milano, Italy. 2015.

22. Wang W, Das A, Ali T, Cole O, Chikhani M, Haque M, Hardman JG, Bates DG. Can computer simulators accurately represent the pathophysiology of individual COPD patients? Intensive Care Medicine Experimental. 2014;2:23.

23. Borges JB, Okamoto VN, Matos GF, Caramez MP, Arantes PR, Barros F, Souza CE, Victorino JA, Kacmarek RM, Barbas CS, et al. Reversibility of lung collapse and hypoxemia in early acute respiratory distress syndrome. Am J Respir Crit Care Med. 2006;174:268-78. 
24. Ferguson ND, Fan E, Camporota L, Antonelli M, Anzueto A, Beale R, Brochard L, Brower R, Esteban A, Gattinoni L, et al. The Berlin definition of ARDS: an expanded rationale, justification, and supplementary material. Intensive Care Med. 2012;38:1573-82.

25. Luecke T, Fiedler F, Pelosi P. Respiratory mechanics at the bedside. In: Gullo A. (eds) Anaesthesia, Pain, Intensive Care and Emergency Medicine-A.P.I.C.E.. Milano: Springer; 2005. p. 279-95.

26. Tusman G, Bohm SH, Suarez-Sipmann F, Turchetto E. Alveolar recruitment improves ventilatory efficiency of the lungs during anesthesia. Can J Anaesth. 2004:51:723-7.

27. Lapinsky SE, Mehta S. Bench-to-bedside review: recruitment and recruiting maneuvers. Crit Care. 2005;9:60-5.

28. Gattinoni L, Tonetti T, Cressoni M, Cadringher P, Herrmann $\mathrm{P}$, Moerer $\mathrm{O}$, Protti A, Gotti M, Chiurazzi C, Carlesso E, et al. Ventilator-related causes of lung injury: the mechanical power. Intensive Care Med. 2016;42:1567-75.

29. Gammon RB, Shin M, Buchalter S. Pulmonary barotrauma in mechanical ventilation. Patterns and risk factors Chest. 1992;102:568-72.

30. Protti A, Votta E, Gattinoni L. Which is the most important strain in the pathogenesis of ventilator-induced lung injury: dynamic or static? Curr Opin Crit Care. 2014;20:33-8.

31. Cressoni M, Gotti M, Chiurazzi C, Massari D, Algieri I, Amini M, Cammaroto A, Brioni M, Montaruli C, Nikolla K, et al. Mechanical power and development of ventilator-induced lung injury. Anesthesiology. 2016:124:1100-8.

32. Gattinoni L, Marini JJ, Collino F, Maiolo G, Rapetti F, Tonetti T, Vasques F, Quintel M. The future of mechanical ventilation: lessons from the present and the past. Crit Care. 2017;21:183.

33. ARDS Network. Ventilation with lower tidal volumes as compared with traditional tidal volumes for acute lung injury and the acute respiratory distress syndrome. The acute respiratory distress syndrome Network. N Engl J Med. 2000;342:1302-8.

34. Villar J, Blanco J, Anon JM, Santos-Bouza A, Blanch L, Ambros A, Gandia F, Carriedo D, Mosteiro F, Basaldua S, et al. The ALIEN study: incidence and outcome of acute respiratory distress syndrome in the era of lung protective ventilation. Intensive Care Med. 2011:37:1932-41.

35. Neto AS, Hemmes SN, Barbas CS, Beiderlinden M, Fernandez-Bustamante A, Futier E, Gajic O, El-Tahan MR, Ghamdi AA, Gunay E, et al. Association between driving pressure and development of postoperative pulmonary complications in patients undergoing mechanical ventilation for general anaesthesia: a meta-analysis of individual patient data. Lancet Respir Med. 2016:4:272-80

36. Chiumello D, Carlesso E, Brioni M, Cressoni M. Airway driving pressure and lung stress in ARDS patients. Crit Care. 2016;20:276.

37. Xie J, Jin F, Pan C, Liu S, Liu L, Xu J, Yang Y, Qiu H. The effects of low tidal ventilation on lung strain correlate with respiratory system compliance. Crit Care. 2017;21:23

38. Writing Group for the Alveolar Recruitment for Acute Respiratory Distress Syndrome Trial I, Cavalcanti AB, Suzumura EA, Laranjeira LN, Paisani DM, Damiani LP, Guimaraes HP, Romano ER, Regenga MM, LNT T, et al. Effect of lung recruitment and titrated positive end-expiratory pressure (PEEP) vs low PEEP on mortality in patients with acute respiratory distress syndrome: a randomized clinical trial. JAMA. 2017;318:1335-45.

39. Bull TM, Clark B, McFann K, Moss M, National Institutes of Health/National Heart L, Blood Institute AN. Pulmonary vascular dysfunction is associated with poor outcomes in patients with acute lung injury. Am J Respir Crit Care Med. 2010;182:1123-8.

40. Vieillard-Baron A, Schmitt JM, Augarde R, Fellahi JL, Prin S, Page B, Beauchet A, Jardin F. Acute cor pulmonale in acute respiratory distress syndrome submitted to protective ventilation: incidence, clinical implications, and prognosis. Crit Care Med. 2001;29:1551-5.

41. Boissier F, Katsahian S, Razazi K, Thille AW, Roche-Campo F, Leon R, Vivier E, Brochard L, Vieillard-Baron A, Brun-Buisson C, Mekontso Dessap A. Prevalence and prognosis of cor pulmonale during protective ventilation for acute respiratory distress syndrome. Intensive Care Med. 2013;39:1725-33.

42. Mekontso Dessap A, Boissier F, Charron C, Begot E, Repesse X, Legras A, Brun-Buisson C, Vignon P, Vieillard-Baron A. Acute cor pulmonale during protective ventilation for acute respiratory distress syndrome: prevalence, predictors, and clinical impact. Intensive Care Med. 2016;42:862-70.

43. Chiumello D, Carlesso E, Cadringher P, Caironi P, Valenza F, Polli F, Tallarini F, Cozzi P, Cressoni M, Colombo A, et al. Lung stress and strain during mechanical ventilation for acute respiratory distress syndrome. Am J Respir Crit Care Med. 2008;178:346-55.
44. Protti A, Maraffi T, Milesi M, Votta E, Santini A, Pugni P, Andreis DT, Nicosia F, Zannin E, Gatti S, et al. Role of strain rate in the pathogenesis of ventilatorinduced lung edema. Crit Care Med. 2016;44:e838-45.

45. Gattinoni L, Pesenti A. The concept of "baby lung". Intensive Care Med. 2005:31:776-84

46. Caironi P, Cressoni M, Chiumello D, Ranieri M, Quintel M, Russo SG, Cornejo R, Bugedo G, Carlesso E, Russo R, et al. Lung opening and closing during ventilation of acute respiratory distress syndrome. Am J Respir Crit Care Med. 2010;181:578-86.

47. Luecke T, Pelosi P. Clinical review: positive end-expiratory pressure and cardiac output. Crit Care. 2005;9:607-21.

48. Fan E, Villar J, Slutsky AS. Novel approaches to minimize ventilator-induced lung injury. BMC Med. 2013;11:85.
Ready to submit your research? Choose BMC and benefit from:

- fast, convenient online submission

- thorough peer review by experienced researchers in your field

- rapid publication on acceptance

- support for research data, including large and complex data types

- gold Open Access which fosters wider collaboration and increased citations

- maximum visibility for your research: over $100 \mathrm{M}$ website views per year

At BMC, research is always in progress.

Learn more biomedcentral.com/submissions 